\title{
Clean Development Mechanism Cooperation in China
}

\author{
Ye Qian', Jian-Cheng Bin ${ }^{2}$
}

${ }^{1}$ School of Finance, Zhejiang University of Finance and Economics, Hangzhou, China; ${ }^{2}$ Jiangxi University of Finance and Economics, Nanchang, China.

Email: docterye@yahoo.com.cn

Received September $4^{\text {th }}, 2011$; revised October $6^{\text {th }}$, 2011; accepted October $15^{\text {th }}, 2011$.

\begin{abstract}
The Clean Development Mechanism (CDM) is an arrangement under the Kyoto Protocol allowing developed countries with a greenhouse gas reduction commitment to invest in projects that reduce emissions in developing countries as an alternative to more expensive emission reductions in their own countries. In terms of the CDM areas, there are huge potential commercial opportunities between China and the United Kingdom since China signed the Kyoto Protocol.
\end{abstract}

Keywords: CDM, Climate Change, The CDM International Cooperation, The Kyoto Protocol

\section{Introduction to the CDM in China}

Climate change is a great environmental issue of common concern to the international community today [1]. Rising global temperatures will bring changes in weather patterns, rising sea levels and increased frequency and intensity of extreme weather events [2]. The effects will be felt both in China and in the UK. Climate change is an issue involving both environment and development, but it is ultimately an issue of development [3].

As noted by the United Nations Framework Convention on Climate Change (UNFCCC), the largest share of historical and current global emissions of greenhouse gases has originated from developed countries, while per capita emissions in developing countries are still relatively low and the share of global emissions originating from developing countries will grow to meet their social and development needs [4]. The UNFCCC stipulates clearly that the Parties to the Convention shall protect the climate system for the benefit of present and future generations of humankind, on the basis of equity and in accordance with their common but differentiated responsibilities and respective capabilities, and accordingly, the developed country Parties shall take the lead in combating climate change and the adverse effects thereof. It further provides that all Parties shall formulate, implement, publish and regularly update national programs to address climate change.

The CDM is one flexible mechanism established under the Kyoto Protocol. It allows developed countries to invest in green house gas emission reduction projects in developing countries and to claim the resulting Certified Emission Reductions (CERs) to assist them in compliance with their binding green house gas emission reduction commitments under the Protocol.

At the same time, CDM project activities contribute to sustainable development in the host developing countries. The CDM is conceived as a project-based win-win mechanism that can provide increased flexibility to developed countries, which can reduce their overall cost of compliance with Kyoto commitments, while providing the CDM project hosting partners with additional funds and advanced technology.

As a developing country of responsibility, China attaches great importance to the issue of climate change. The National Coordination Committee on Climate Change was established, and a series of policies and measures to address climate change has been taken in the overall context of national sustainable development strategy, making positive contributions to the mitigation of and adaptation to climate change. As it is mandated under the UNFCCC, the Government of China formulates first global warming policy initiative, China's National Climate Change Programme (CNCCP) in June 2007. The Programme encourages and promotes the cooperation of CDM projects and other kinds of international cooperation, strive to build a resource conservative and en- 
vironmentally friendly society, enhance national capacity to mitigate and adapt to climate change, and make further contribution to the protection of the global climate system.

China takes active part in international and domestic activities regarding global climate change. China signed the UNCCC in 1992, climate policies have been high on the agenda of government decision makers and explicit climate mitigation or adaptation policies are in place [5]. China's pursuit of sustainable development has in many respects been consistent with climate protection. Furthermore, China ratified the Kyoto Protocol in August 2002, making the country eligible for CDM participation in competition with other developing countries. In October 2004, Measures for Operation and Management of Clean Development Mechanism Projects in China was taken effect. This provides official greenhouse gas emission inventory data, which are important for assessing priority areas for CDM projects.

\section{CDM Potential in China}

Exploring the CDM poses a significant challenge to British enterprises for strategically assessing the opportunities of the emerging carbon offset market. A model system's results from the World Bank provide the policy implications for CDM potential in China, and the impact of CDM on China's economy. It would be helpful for enterprises to formulate appropriate CDM strategy in China.

One of the general requirements for CDM project approval under the current Chinese arrangements is that the CDM project activity should promote the transfer of environmentally friendly technology. In addition, energy efficiency improvements and new and renewable energy are listed as priority areas for CDM cooperation. In general, the central government's main goals are technology progress and broader contributions to sustainable development, rather than merely attracting additional foreign investment.

Along with China's rapid economic development and the acceleration of industrialization and urbanization, the demand for energy keeps increasing, and the construction of a stable, economical, clean and safe energy supply system faces the following challenges.

At present, China is prominent resources restraint and low energy efficiency. China's relative dearth of highquality energy resources hinders its supply capability; its imbalanced distribution makes it difficult to secure a continued and steady supply; and the extensive pattern of economic growth, irrational energy structure, unsatisfactory energy technology and relatively poor management have resulted in higher energy consumption perunit GDP and for the major energy-consuming products than the average level of major energy-consuming countries, thus further intensifying the energy supply-demand contradiction. Consequently, an increase solely in supply is hard to meet the rising demand for energy.

Secondly, China is increasing environmental pressure caused by the consumption of energy, mostly coal. Coal is the main energy consumed in China, and the energy structure with coal playing the main role will remain unchanged for a long time to come. The relatively backward methods of coal production and consumption have intensified the pressure on environmental protection. Coal consumption has been the main cause of smoke pollution in China, as well as the main source of green-house gas. As the number of motor vehicles climbs, the air pollution in some cities is becoming a mixture of coal smoke and exhaust gas. If this situation continues, the ecological environment will face even greater pressure.

Finally but not all, China is incomplete market system and emergency response capability yet to be enhanced. China's energy market system is yet to be completed, as the energy pricing mechanism fails to fully reflect the scarcity of resources, its supply and demand, and the environmental cost. Order in energy exploration and development must be further standardized, and the energy supervisory system improved. Coal production safety is far from satisfactory, the structure of power grids is not rational, the oil reserves are not sufficient, and an effective emergency pre-warning system is yet to be improved and consolidated to deal with energy supply breakdowns and other major unexpected emergencies.

Based on above reasons, the greenhouse gas emissions from China's energy sector were projected to increase, with coal contributing a significant share to the increasing demand from the power and industry sectors. China's energy-related CDM market potential is huge. China captures nearly 50 percent of the total market CDM demand [4].

Following Figure 1 highlights that China's share in the

Registered project activities by host party. Total: 895

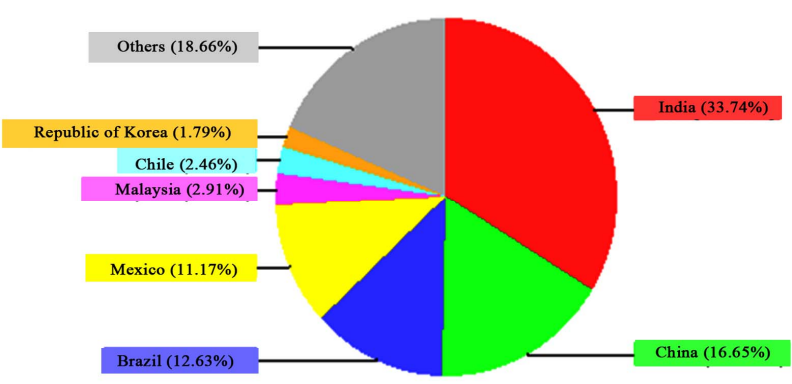

http://cdm.unfecc.int (c) 07.01.2008 13:14

Figure 1. Shares of global CDM projects 
global CDM projects is 16.65 percent. Supplying this amount of CERs would require a significant number of newly built larger power projects registered as CDM projects, as well as several renewable power projects put into operation. It is important to note that besides reductions in $\mathrm{CO}_{2}$ from electricity generation, $\mathrm{CDM}$ potentials from other energy end-use and from abatement of other gases and other source and sink categories must also be taken into account in estimating China's total CDM potential and its impact on market dynamics.

Through so-called project-based transactions, investors receive CERs when they fund projects that reduce greenhouse gases relative to baseline emissions levels. Foreign investors usually fund new projects, although in principle they can also receive CERs when investing in existing ones.

The present CDM market in China is buyer dominated. The preference of investors for "high quality" and "low risk" projects is likely to shape the market for carbon offsets. In reality, there will be no one uniform carbon price for different transferable emission units. But the CERs price could be higher, considering the prevailing certainties about the ratification of the Kyoto Protocol after Bali Road Map in December 2007.

\section{Benefits from CDM in China}

Beside the obvious goals of CDM project activities-the reduction of green house gas emissions and mitigation of climate change-there are other significant benefits for China. These include:

1) Transfer of state-of-the-art technology to China that will stimulate scientific and technological progress. China needs larger-scale technology import and re-innovation and by 2010, China's hi-tech import and export is expected to reach 800 billion US dollars. At present, ChinaUK technology trade is less than ideally matched with our respective economic strengths, and we're ready to create conditions to let more Chinese people recognise the UK's technological competency.

2) Additional revenues coming from CERs that will improve the financial performance of a project. In November 2007 China launched a state-owned CDM fund to finance the country's efforts to address climate change. The China CDM Fund, managed by the Ministry of Finance, generated money from the current CDM projects, which help China improve energy efficiency and protect the environment by using clean energy for power generation, and raise money from various sources.

3) Help to start up new, domestic industry sectors. China encourages foreign investment in the production and supply of electric power and gas, as well as in the construction and operation of thermal power plants with a single-generator capacity, power stations burning clean coal, power stations featuring heat and power cogeneration, hydropower stations mainly for electricity production, nuclear power stations in which the Chinese side holds the dominant share, as well as power stations with renewable energy or new energy resources. It encourages foreign investors to invest in technology and equipment production for thermal, hydro and nuclear power stations with a considerably large generating capacity as well as for thermal power desulphurisation. It also encourages them to invest in the construction and operation of coal pipeline transportation facilities.

4) Diversification of electricity generation sources. On the basis of taking into overall consideration such factors as resources, technology, environmental protection and the market, the Chinese government will develop clean coal-fired electric power by setting up large coal-fired power bases and encouraging the building of power plants at pitheads, with emphasis on large, highly efficient, environment-friendly power generating sets. It will actively develop cogeneration of heat and power, and speed up elimination of small and backward thermal power units. On the condition that the ecological environment is protected and problems affecting local people are properly settled, energetic efforts will be made to develop hydropower. It will actively popularise technologies utilizing wind, biomass and solar energy for power generation, and build several million-kw wind power bases to achieve industrialization by means of scale power generation. It will also actively develop nuclear power, and appropriately develop natural gas power generation.

5) Support and help to accelerate the development of renewable energies. The exploration and utilization of renewable energy resources plays a significant role in increasing energy supply, improving the energy mix and helping environmental protection, and is also a strategic choice of China to solve the contradiction between energy supply and demand and achieve sustainable development. China has promulgated the Renewable Energy Law and priority policies for renewable energy electricity, entailing priority to be connected to grids, acquisition in full and preferential price, and public sharing of costs. It has earmarked special funds for renewable energy development to support resource survey, R \& D of relevant technologies, building of pilot and demonstration projects. It has released the Medium- and Long-term Program for Renewable Energy Development, putting forward the goal of increasing renewable energy consumption to 10 percent of the total energy consumption by 2010 and 15 percent by 2020. China will further the comprehensive and cascade development of areas with hydropower resources, speed up the construction of large hydropower stations, develop medium and small-sized hydropower stations based on local conditions, and con- 
struct pumped-storage power stations under appropriate circumstances. It will spread the latest technologies for the utilization of solar energy, methane and other renewable energy sources. It will actively implement policies supporting renewable energy development, foster a renewable energy market.

The benefits derived from CDM support all major objectives of China's energy policy within the 11th FiveYear Plan (2006-2010). that is, by 2010 the energy supply will basically meet the demands of national economic and social development; and obvious progress will have been made in energy conservation; energy efficiency will have been noticeably enhanced and the energy structure optimised; technological progress, economic benefits and market competitiveness will have been greatly increased; and energy-related macro-control, market regulation, legislation and emergency pre-warning system and mechanism compatible with the socialist market economy will all have been improved. The result will be that the coordinated development will have been achieved between energy production, the economy, the society and the environment.

\section{CDM Collaboration between China and the UK}

China-UK relationship has developed smoothly and their economic and trade cooperation has achieved fruitful results under the active promotion of leaders of both countries since the establishment of their diplomatic relations.

The mutual investment between the two countries has enjoyed steady development. The accumulative UK investment in China has amounted to nearly 15 billion dollars and the UK remains China's largest investment country in EU, while the number of the Chinese enterprises investing and opening businesses in the UK has been increasing with each passing yea.

China is now devoted to building an energy saving and environmentally friendly society, promoting industrial structure upgrading through innovations, transferring economic development to achieve sustainable development. All these efforts have offered an enormous opportunity for China and the UK to further develop mutually beneficial cooperation at a higher level and in a wider range.

Taking opportunities offered by the CDM, the Chinese government has established a National Examination and Approval Council for Clean Development Mechanism, which consists of relevant departments. Up to October 2007, 20 projects under the CDM have been formally approved, and there are 6 projects from British enterprises cooperation.

In September 2006, when Chinese Premier Wen Jia bao visited the UK, the two countries signed a Memorandum of Understanding (MoU) on establishing a China-UK climate change working group between the NDRC of China and the DEFRA of the UK. Within the $\mathrm{MoU}$, there are broad subject areas for cooperation, that is, 1) Broader science work, in particular to review and develop on-going climate science collaboration between the Participants; 2) Energy efficiency; 3) Energy technologies; 4) Approaches to adaptation; 5) The use of the flexible mechanisms, in particular the CDM; 6) Capacity building activities [6].

In January 2008, British Prime Minister Gordon Brown paid a visit to Beijing. During his visit, a joint declaration on climate change was signed, which establishes a unique bilateral Partnership to collaborate on the development and deployment of clean energy technologies.

Under this Partnership, the UK will provide at least GBP 50 million to China from British Environmental Transformation Fund to support investment in areas such as energy efficiency, renewable, clean coal and carbon capture and storage [7]. Secondly, bring together government in a series of exchanges over the coming two years officials and experts from both sides to explore opportunities for clean energy investment in China and the UK-including training, research collaboration and investment partnerships in the fields of technology and engineering, business, finance and academic research; Third, extend cooperation on the EU-China Near Zero Emissions Coal Programme, launched in Beijing in November 2007 with up to GBP 3.5 million of UK funding. This will deliver, by 2020, a commercial scale coal-fired power station in China with carbon capture and storage. And finally, collaborate on extending the CDM, to allow developed country carbon credits to be invested in energy efficiency and clean energy programmes.

\section{Concluding Remarks}

In conclusion, China implemented its first CDM project to reduce emissions under the Kyoto Protocol on 27 June 2005, marking a new phase in international efforts to tackle climate change. Since then, China became the world's leading supplier of CERs, as investors speculating on the future value of carbon emissions credits sought to take advantage of its low marginal costs of carbon abatement. In the long run, China stresses energy conservation and energy efficiency improvement in international cooperation. Energy-conservation cooperation will cover various aspects of energy consumption in industry production, transportation and buildings. China holds a positive attitude toward the CDM international cooperation, within the framework of addressing climate change. 


\section{REFERENCES}

[1] The World Bank etc., "Clean Development Mechanism in China,” 2nd Edition, The World Bank Group, Washington DC, 2004.

[2] The Information Office of the State Council of China, “China's Energy Conditions and Policies," White Paper, Beijing, 2007.

[3] National Development and Reform Commission, People's Republic of China, “China's National Climate Change Programme,” 2007. http://en.ndrc.gov.cn/newsrelease/

[4] UNFCCC, “The CDM,” 2008. http://cdm.unfccc.int

[5] NCCCC, "Measures for Operation and Management of
Clean Development Mechanism Projects in China,” 2005. http://cdm.ccchina.gov.cn/english/NewsInfo.asp?NewsId= 905

[6] DEFRA, "Memorandum of Understanding between the National Development and Reform Commission of the People's Republic of China and the Department for Environment, Food and Rural Affairs on Establishing a China-UK Climate Change Working Group,” 2006.

http://www.scribd.com/doc/64481151/Cleaner-Coal-in-C hina

[7] UKTI, "Joint Declaration on Climate Change between China and the UK," The UK and China: A Framework for Engagement, 2008.

http://www.chinavalue.net/Group/Topic/463 